\title{
Repair of DNA-protein crosslinks in plants
}

\author{
Leonie Hacker, Annika Dorn, Holger Puchta* \\ Botanical Institute, Molecular Biology and Biochemistry, Karlsruhe Institute of Technology, Karlsruhe, Germany
}

Keywords:

MUS81

WSS1A

TDP1

Endonuclease

Protease

Tyrosyl-DNA-phosphodiesterase

\begin{abstract}
A B S T R A C T
DNA-protein crosslinks represent a severe kind of DNA damage as they disturb essential processes, such as transcription and DNA replication, due to their bulkiness. To ensure the maintenance of genome integrity, it is necessary for all living organisms to repair these lesions in a timely manner. Over recent years, much knowledge has been obtained regarding the repair of DNA-protein crosslinks (DPC), but it was only recently that the first insights into the mechanisms of DPC repair in plants were obtained. The plant DPC repair network consists of at least three parallel pathways that resolve DPC by distinct biochemical mechanisms. The endonuclease MUS81 resolves the DPC by cleaving the DNA part of the crosslink, the protease WSS1A is able to degrade the protein part and the tyrosyl-DNA-phosphodiesterase TDP1 can hydrolyse the crosslink between a protein and the DNA. However, due to the variety of different DPC types and the evolutionary conservation of pathways between eukaryotes, we expect that future research will reveal additional factors involved in DPC repair in plants.
\end{abstract}

\section{Introduction}

DNA repair is particularly important in sessile organisms like plants as they are constantly exposed to harmful environmental sources such as UV light. Besides these environmental sources, endogenous factors also threaten the genome integrity of plants, as these factors can cause severe DNA damage within cells. Photosynthesis for example, is a constant source of reactive oxygen species. DNA protein crosslinks (DPC) represent a specific kind of damage that have not been taken into account whilst other basic mechanisms of DNA repair were elucidated. DPC are defined by a covalent linkage between a protein and DNA and are very large due to their proteinaceous part that impairs many chromatin based processes by steric hindrance. To maintain cell via bility and access to important genetic regions, plants have evolved at least three independent pathways to repair this kind of highly toxic lesion [1]. Research on DPC repair in plants is still in its infancy; however, it is of high relevance due to the broad variety of conserved DNA repair pathways in plants. This review will focus on recent find ings about DPC repair in plants, as well as on DPC repair proteins from other organisms, whose homologs might also play a role in plant DPC repair.

\section{Formation of different DPC types}

As all types of nuclear proteins can be linked to DNA by various mechanisms, DPC differ in their size, their physicochemical properties and the nature of the crosslink itself. In general, DPC can be subdivided into four different classes dependent on the presence and type of DNA breaks adjacent to the DPC (Fig. 1). Type 1 DPC are not associated with DNA breaks; instead, the protein is linked to an intact DNA strand. This type of DPC occurs very often, as theoretically any kind of protein close to the DNA can form an adduct under the influence of various en vironmental, endogenous or chemical agents [2]. UV light and IR, for example, can directly induce Type 1 DPC, since the direct deposition of radiation onto DNA or proteins leads to the formation of free radicals within the molecules, which are subsequently able to react with each other, thus forming covalent bonds [3]. Reactive oxygen species or reactive aldehydes, which are produced as by products of various me tabolic processes like photosynthesis or the demethylation of histones, are endogenous sources for the formation of Type 1 DPC [4 8]. Common chemical crosslinkers for the induction of Type 1 DPC are formaldehyde, platin compounds like cisplatin, and cytosine analogues like 5 azacytidine ( $5 \mathrm{azaC}$ ) and zebularine. Formaldehyde and cisplatin are considered broad range chemical crosslinkers, as they not only in duce DPC but also DNA DNA or protein protein crosslinks $[9,10]$. On the other hand, the cytosine analogues zebularine and 5 azaC constitute

\footnotetext{
Abbreviations: AP site, apurinic/apyrimidinic site; BER, base excision repair; DSB, double strand break; DPC, DNA-protein crosslink; HR, homologous recombination; IR, ionising radiation; SSB, single strand break; UV, ultraviolet

* Corresponding author.

E-mail address: holger.puchta@kit.edu (H. Puchta).
} 


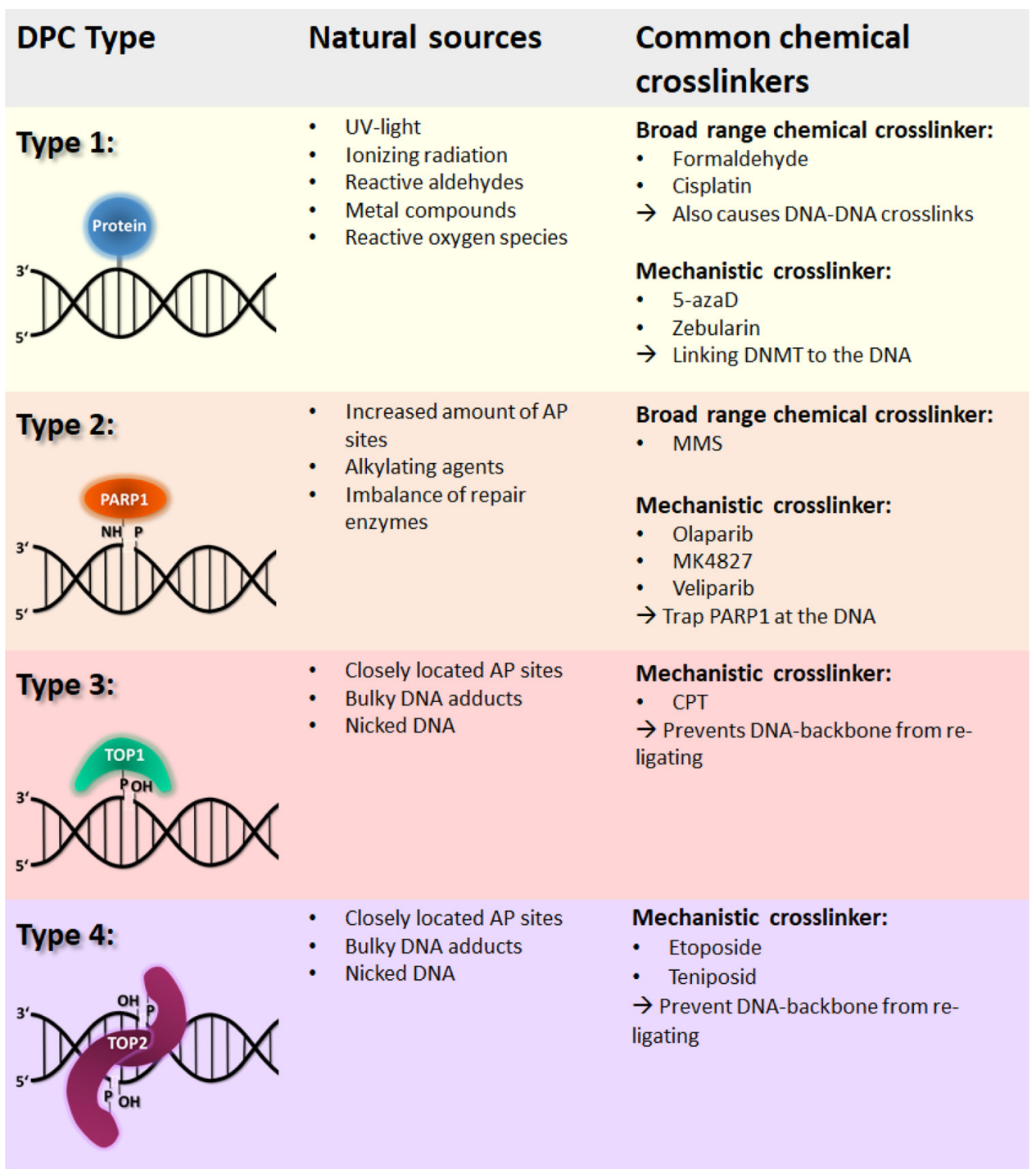

Fig. 1. Induction of different DPC Types. Overview of the natural sources and common chemical crosslinkers that lead to the formation of DPC Type $1,2,3$ and 4 .

mechanistic crosslinkers as they are able to trap the reaction inter mediate of the methyltransferase DNMT at the DNA [11,12]. As the sources and types of trapped proteins are highly diverse, there is also a great variety of different crosslink bonds within this type of DPC $[2,13]$.

While Type 1 DPC include both enzymatic and non enzymatic DPC, Type 24 consist only enzymatic DPC, which can be produced sponta neously by abortive enzymatic reactions on the DNA, in which covalent DNA protein intermediates get stabilized [14]. IR and UV light also contribute to the formation of enzymatic DPC, however this contribu tion is more indirect as they induce various kinds of DNA damage such as apurinic sites (AP sites), base mismatches, deaminations, single strand breaks (SSBs) and double strand breaks (DSBs) [15]. Type 2 DPC represent a DNA adduct next to an AP site, which arises during base excision repair (BER) either with the poly(ADP ribose) polymerase PARP1, or with the DNA polymerase Pol $\beta$ stabilized at the DNA [14]. The crosslink between PARP1 and the DNA might be a Schiff base at the $3^{\prime}$ end, that can arise spontaneously when there is a persistant increased amount of AP sites in the DNA [18]. The formation of PARP1 DPC gets promoted further upon treatment with alkylating agents like MMS (methyl methanesulfonate) [17]. Olaparib, MK4827 and veliparib are additional mechanistic crosslinkers contributing to the formation of Type 2 DPC, as they inhibit PARP1 and thereby trap it at the DNA [20]. Plants possess three homologs of PARP1, namely PARP1, PARP2 and PARP3. For PARP1 and PARP2, it could already be shown that they probably contribute to plant BER [21 23]. Thus, PARP1 DPC might also be biologically relevant in plants. Pol $\beta$ DPC, on the other hand, are formed under the presence of oxidising agents that are causing the formation of 2 desoxyribonolactone (dL) AP sites. This kind of lesion can be efficiently repaired via long patch BER. Nevertheless, during attempted short patch BER of the dL lesion, Pol $\beta$ becomes covalently trapped at the $5^{\prime}$ end of the AP site, thus causing a harmful crosslink $[16,24]$. However, plants do not harbour a Pol $\beta$ homolog, and Pol $\lambda$, which is the only member of the $\mathrm{X}$ polymerase family in plants, is not able to bypass dL lesions [25 27]. Furthermore, it is not yet known whether plants perform short patch BER [25]. Thus, the significance of this Type of DPC probably remains obsolete in plants.

Type 3 and 4 DPC consist of trapped topoisomerase cleavage com plexes, which can occur spontaneously in processes where DNA must be unwound or disentangled, such as DNA replication, recombination, transcription or chromosome segregation [14]. DNA topoisomerases are capable of relaxing the DNA by inducing transient DNA breaks. To poisomerase 1 (TOP1) produces SSBs, while Topoisomerase 2 (TOP2) produces DSBs. Their function relies on an active tyrosyl residue in the reactive centre of the enzyme, with which they can attack the phos phate of the DNA backbone in a reversible manner. However, the re action intermediate can be trapped under certain conditions [28]. Thereby, DNA defects such as mismatched bases, single strand breaks, AP sites or bulky DNA adducts foster the formation of both Type 3 and 
Type 4 DPC [29]. Although the origins of both types of DPC are very similar, the complexes are very distinct chemically and thus the con sequences for genome integrity differ greatly. In Type 3 DPC, TOP1 is connected with the DNA via a tyrosyl phosphodiester bond at the $3^{\prime}$ end of a SSB. In contrast, in Type 4 DPC the trapped TOP2 is associated with the DNA via two tyrosyl phosphodiester bonds at the $5^{\prime}$ ends of a double strand break (DSB) [28]. As a result, Type 4 DPC represent a significantly more toxic DNA damage than Type 3 DPC. In cancer treatment, the cytotoxicity of Type 3 and Type 4 DPC is used to se lectively kill actively dividing cells with specialized inhibitors. In par ticular, inhibitors are used to prevent the DNA backbone from re li gating. Camptothecin (CPT) and CPT derivatives function in this manner and are used to stabilize Type 3 DPC, while etoposide and te niposide are common agents in stabilizing Type 4 DPC [30 32]. The functional mechanism of DNA topoisomerases is highly conserved amongst all living kingdoms, therefore Type 3 and Type 4 DPC are also of high biological relevance in plants [33].

\section{Analysis of DPC repair in plants}

Since DNA replication and subsequent cell division are highly de pendent on genome integrity, the susceptibility of DNA repair mutants to certain genotoxins in sensitivity analyses is often determined by their amount of viable cells. For sensitivity analyses in bacteria, fungi and animals, cell cultures are used to determine the amount of living cells after exposure to certain genotoxins. In plants, however, sensitivity analyses can be carried out with whole, multicellular organisms. In contrast to unicellular organisms or cell cultures, the number of viable cells is not counted, but the biomass is determined after genotoxin treatment. As plants also possess rapidly dividing meristematic tissues, cell death upon replication blockages can also be microscopically vi sualized in roots of young seedlings. Roots are especially suitable for this kind of examination as their cells are quickly dividing and easy to observe. Furthermore, meristematic cells are especially sensitive against genotoxic stress, as they are the precursors of all differentiated tissues and thus, maintenance of genome integrity is even more im portant in these cells [34].

\section{Repair of DPC in plants}

DPC represent steric obstacles to DNA replication and transcription machineries and thus can lead to blocked replication forks, chromo somal aberrations or even cell death if not repaired in time. Due to the various sources and the broad range of possible target proteins, they are proposed as one of the most abundant DNA lesions [35]. Hence, cells possess a variety of specialized but also canonical mechanisms to repair this kind of highly toxic lesion. In yeast and bacteria, nucleotide exci sion repair (NER) is involved in the repair of smaller Type I DPC $(<16$ $\mathrm{kDa}$ ) before $\mathrm{S}$ phase [36 38]. In mammals, the cross linked protein should not be bigger than $11 \mathrm{kDa}$ to be channelled into the NER pathway. Thus, NER is more important in the repair of DNA peptide crosslinks, in which the protein has already mainly been degraded [39]. Since Type 24 DPC all contain larger proteinaceous components, they would require pre processing by the $26 \mathrm{~S}$ proteasome or by specialized proteases before the repair mechanism by NER could take place. Al though this interplay seems to be quite plausible, it has yet to be proven.

On the other hand, homologous recombination (HR) seems to con tribute to the repair of bulkier but also small DPC during S and G2 phase $[35,39]$. It could be shown that different HR mutants from bac teria, fungi and mammals exhibited enhanced sensitivity to crosslinking agents like formaldehyde, $5 \mathrm{azaD}$ or etoposide [38,40,41]. Ad ditionally, it was demonstrated that the frequency of $\gamma \mathrm{H} 2 \mathrm{AX}$ foci in mammalian cells was increased by treatment with CPT [42]. Thus, it seems as if HR is participating in the repair of Type 1, 3 and 4 DPC. However, since Type 1 DPC inducing agents such as formaldehyde and cisplatin also cause distinct DNA damage such as interstrand and in trastrand crosslinks, it cannot be excluded that, under these conditions, enhanced HR is just the result of other repair pathways like the Fanconi anemia pathway [35]. Therefore, the contribution of HR in the repair of Type 1 DPC needs to be investigated further. As etoposide and CPT are very specifically acting agents, HR can be assumed to be important for the repair of Type 3 and 4 DPC.

Due to the lack of scientific evidence, only little is known about how these canonical repair mechanisms might contribute to DPC repair in plants. However, an involvement of NER and HR in the repair of ze bularine induced DNA damage could be demonstrated in Arabidopsis, whereby somatic HR was shown to be upregulated following zebularine treatment $[11,43]$. Furthermore, the hypersensitivity of Atatm and Atatr mutants and the additive sensitivity of double mutants against zebu larine indicates that both DNA damage response kinases mediate the HR based repair. As the Arabidopsis mutant for the NER factor XPF also demonstrated partial zebularine sensitivity, NER might also be involved in the repair [11]. This indicates a conserved role for both NER and HR in the repair of Type 1 DPC.

Besides these canonical DNA repair factors, three more specialized factors were recently characterized, which are directly involved in the repair of DPC in plants [1]. The following section will elucidate how the endonuclease MUS81, the metalloprotease WSS1A and the tyrosyl DNA phosphodiesterase TDP1 are involved in DPC repair in plants by targeting distinct features of the crosslink. Thereby, the DNA part of the crosslink can be cleaved endonucleolytically, the protein part can be degraded by proteolytic decay, or the bond between DNA and protein can be resolved.

\subsection{Endonucleolytic cleavage of a DPC}

Endonucleolytic cleavage of DPC in plants is mainly facilitated by the structure specific Holliday junction (HJ) resolvase MUS81 that specifically targets the DNA part of a DPC [1]. MUS81 (Methyl me thansulfonate, UV sensitive) belongs to the family of XPF/MUS81 en donucleases and is highly conserved in the eukaryotic kingdom [44]. Together with EME1, it forms a heterodimeric functional complex, which catalyses the cleavage of specific DNA intermediates [45,46]. Thus it preferentially cuts 3 ' flaps, stalled replication forks, D loops and nicked HJs, and to a lesser extent probably as a heterotetramer, it also cuts intact HJs [47 51]. The mechanism by which it resolves these structures is a nick counternick mechanism, cleaving the DNA strand that opposes the strand [47]. It was shown that plants deficient in MUS81 exhibited enhanced sensitivity to DNA crosslinking agents such as MMC and cisplatin. MUS81 was therefore first classified as an im portant factor in the repair of interstrand and intrastand crosslinks [8,51]. Since human and yeast cells deficient in MUS81 also showed increased sensitivity to CPT, the protein became an interesting candi date in the research of DPC repair in plants $[52,53]$. It could be shown that Atmus81 mutants displayed a hypersensitivity to CPT, consistent with the previous results from other eukaryotes, thereby demonstrating that MUS81 is an important factor in the repair of Type 3 DPC in plants [1]. Furthermore, an increased sensitivity to cisplatin indicates that MUS81 is capable of resolving Type 1 DPC. Due to its substrate pre ference, it appears likely that MUS81 tends to process DPC next to single strand breaks or stalled replication forks, independent of protein and crosslink type. However, the mechanism of how MUS81 resolves DPC is probably not the direct excision of the DPC but the incision of the strand that opposes the nick, thus forming a DSB. This subsequently requires other repair pathways, such as homologous recombination or replication fork regression [53].

Another endonuclease that might contribute to DPC repair in plants is MRE11, which is part of the conserved MRN complex. Besides MRE11, the MRN complex consists of the recombinase RAD50 and the signal transduction protein NBS1. The MRN complex is a crucial factor in DSB repair $[54,55]$. Whereas NBS1 is signalling the damage, MRE11 
is responsible for $3^{\prime}$ end resection and RAD50 is needed for the induc tion of HR or for long range tethering of two DNA ends [56]. In contrast to its function in DSB repair, the role of the MRN complex in plant DPC repair has yet to be investigated in detail. However, it is known that the MRN complex plays a major role in the removal of the TOP2 like SPO11 dimer during meiosis, since meiocytes deficient in MRE11 showed highly fragmented chromosomes [57]. In this case, SPO11 is bound to both ends of a DSB, thereby resembling a DPC. As a result, the MRN complex might contribute to the repair of Type 4 DPC in plants, but there is still a lack of evidence for somatic cells. In bacteria, fungi and mammals, the MRN complex and its respective homologs have already been demonstrated to be involved in DPC repair, suggesting that this function of the MRN complex is highly conserved in all living king doms. DPC repair by the MRN complex is initialized by a DPC depen dent endonucleolytic incision of the DNA by MRE11. After 3' end re section of the generated SSB, a second incision is induced at the complementary DNA strand. This is also resected in a $3^{\prime}$ to $5^{\prime}$ direc tion, thus forming a clean DSB, which can be further processed by ca nonical DSB repair mechanisms such as non homologous end joining or HR [58]. As DPC repair by the MRN complex occurs completely in dependent of the protein linked to the DNA, it was suggested that the MRN complex is able to contribute to the repair of all DPC Types. In Schizosaccharomyces pombe and Xenopus laevis, the contribution of MRE11 to the repair of both Type 4 and Type 3 DPC has already been demonstrated $[59,60]$. As yeast cells deficient in Mre11 displayed en hanced sensitivity to formaldehyde, in comparison to other HR defi cient mutants such as Scrad51 or Scrad52, it is presumed that Mre11 also contributes to the repair of Type 1 DPC $[38,58]$. However, in contrast to these results, as yet there is no evidence that the MRN complex is also involved in the repair of Type 2 DPC.

\subsection{Proteolytic degradation of a DPC}

The existence of a protease that specifically degrades proteins bound to the DNA was only discovered a few years ago. Wss1 (weak suppressor of SMT protein 1) is a metalloprotease, that was identified in a synthetic lethality screen in yeast cells deficient in Tdp1, which is strongly dependent on the presence of Wss1. In subsequent experi ments, it was shown that Wss1 specifically degrades the protein part of a DPC, independent of identity, in a replication coupled manner [61]. Wss 1 is thereby able to digest at least Type 1, 3 and 4 DPC, as it is neither dependent on a DNA break, nor on the crosslink or protein type [61,62]. In animals, this function is fulfilled by the protease Spartan (SPRTN/DVC1), which is related to Wss1 as it shares a common domain organization $[63,64]$. Due to their broad substrate specificity, DPC proteases from the SPRTN/Wss1 family are controlled by several me chanisms to ensure that only proteins covalently linked to the DNA are degraded, as opposed to other nuclear proteins, which would have harmful consequences. One underlying mechanism of control is ubi quitin switch, in which the deubiquitination of SPRTN/Wss1 by an unknown mechanism enables it to localize to the chromatin. In a second level of control, SPRTN/Wss1 requires DNA to become proteolytically active. Experiments have shown that the presence of single stranded DNA is necessary for the proteolysis of crosslinked proteins, whereas double stranded DNA leads to autocleavage of the protease [65]. After proteolysis of the DPC, a small peptide remnant remains attached to the DNA, which is bypassed by translesion synthesis [66]. The removal of the peptide remnant by NER is also speculated, but experimental evi dence is lacking [58]. Interestingly, it was predicted that mono cotyledonous plants such as maize or rice have both a Spartan homolog and two Wss1 homologs WSS1A and WSS1B [35]. Dicotyledonous plants like Arabidopsis thaliana harbour the two homologs WSS1A and WSS1B as well, but a Spartan homolog has yet to be identified. Studies on the function of the two WSS1 homologs indicated that only WSS1A is involved in DPC repair in plants, whereas no function has yet to be demonstrated for the WSS1B homolog. CRISPR/Cas generated knockout mutant lines of WSS1A, but not of WSS1B, displayed increased sensi tivity to cisplatin and CPT. This demonstrates that WSS1A is at least involved in the repair of Type 1 and Type 3 DPC in plants, whereas WSS1B might be evolutionary redundant. Furthermore, the Atwss $1 \mathrm{~A}$ mutants exhibit a fasciated phenotype, a significantly reduced root length compared to the wild type and an enhanced number of dead cells in the root meristem, thus indicating an elementary function of WSS1A for proper cell division in plants [1].

Another protease that might contribute to DPC repair in plants is the aspartic protease DDI1 (DNA damage inducible 1). Ddi1 was previously characterized in yeast and mammals and was predicted to be involved in numerous processes such as protein secretion, mitotic checkpoint control and control of proteasomal gene expression [67 69]. Plants harbour a Ddi1 homolog as well, for which an interaction with the proteasome and ubiquitylated proteins was shown to increase their stability $[70,71]$. However, all of these functions are dependent on the conserved $\mathrm{N}$ terminal encoded UBL (Ubiquitin binding like) domain, but in yeasts and plants it is also dependent on the presence of a $\mathrm{C}$ terminal UBA (Ubiquitin associated) domain. In addition to these do mains, Ddi1 encodes for a highly conserved RVP (retroviral protease) domain and therefore was predicted to function as a protease as well [72]. Indeed, a more current study in yeast revealed that Ddi1 acts as a DPC protease alongside Wss1. It was found that the overexpression of Ddi1 in wss1 tdp1 was sufficient to reduce the growth defect of the double mutant, whereas the additional deletion of Ddi1 in wss1 tdp1 further enhanced the phenotype [62]. Moreover, yeast mutant lines deficient in Ddi1 showed increased susceptibility to hydroxyurea, cis platin, CPT and etoposide, thereby indicating that Ddi1 is involved in the repair of DPC Type 1, 3 and 4, in a replication coupled manner. However, Ddi1 seems to work independently of Wss1, as the double mutant exhibits a synergistic effect when exposed to DPC inducing agents $[62,73]$. Slight differences in sensitivity to distinct DPC inducing agents revealed that Ddi1 preferably proteolyses Type 4 DPC, whereas Wss1 seems to be more important in the resolution of Type 1 and 3 DPC. Further experiments demonstrated that the functional domain of Ddi1 in the proteolysis of DPC is indeed the RVP domain [62]. Since the RVP domain of Ddi1 is highly conserved in the eukaryotic kingdom, it is possible that its function in DPC repair is evolutionarily conserved and thus also preserved in plants [72,74].

DPC proteolysis by the $26 \mathrm{~S}$ proteasome was one of the first known mechanisms in DPC repair. It was shown relatively early that the $26 \mathrm{~S}$ proteasome contributes to the degradation of DPC, as mammalian cells treated with the proteasome inhibitor MG132 accumulated Type 3 DPC $[75,76]$. The participation of the proteasome was expected to be only involved in the repair of enzymatic DPC, since these are undergoing polyubiquitylation which is necessary for proteasome mediated de gradation $[39,77]$. Indeed, the contribution of the proteasome in DPC proteolysis could be demonstrated not only in the repair of Type 3 DPC, but also in Type 2 and 4 DPC [24,78,79]. Recently, however, it was shown in Xenopus egg extract that Type 1 DPC are also rapidly poly ubiquitinated during replication, as long as they have exposed lysine residues. Although this indicates that the proteasome aims at the same targets as Wss1 and SPRTN, it does not mean that one of the two factors is redundant. In contrast to SPRTN and Wss1, the active site of the proteasome is buried in the $20 \mathrm{~S}$ core particle and is therefore probably only sufficient for a first degradation step of very bulky DPC [80]. The active site of SPRTN and Wss1, on the other hand, is exposed and thus suitable to degrade the protein very close to the DNA, subsequently leaving only a small peptide remnant. Hence, it was predicted that the proteasome might work upstream of SPRTN/Wss1 and that they prefer different DPC, as ubiquitylation is not necessarily needed for SPRTN/ Wss 1 mediated proteolysis $[65,80]$. Since the $26 \mathrm{~S}$ proteasome is highly conserved in the eukaryotic kingdom, its function in DPC repair might also be conserved in plants. However, this question requires further investigation because the regulation of the ubiquitin proteasome sig nalling pathway is more complex in plants than in other eukaryotes 


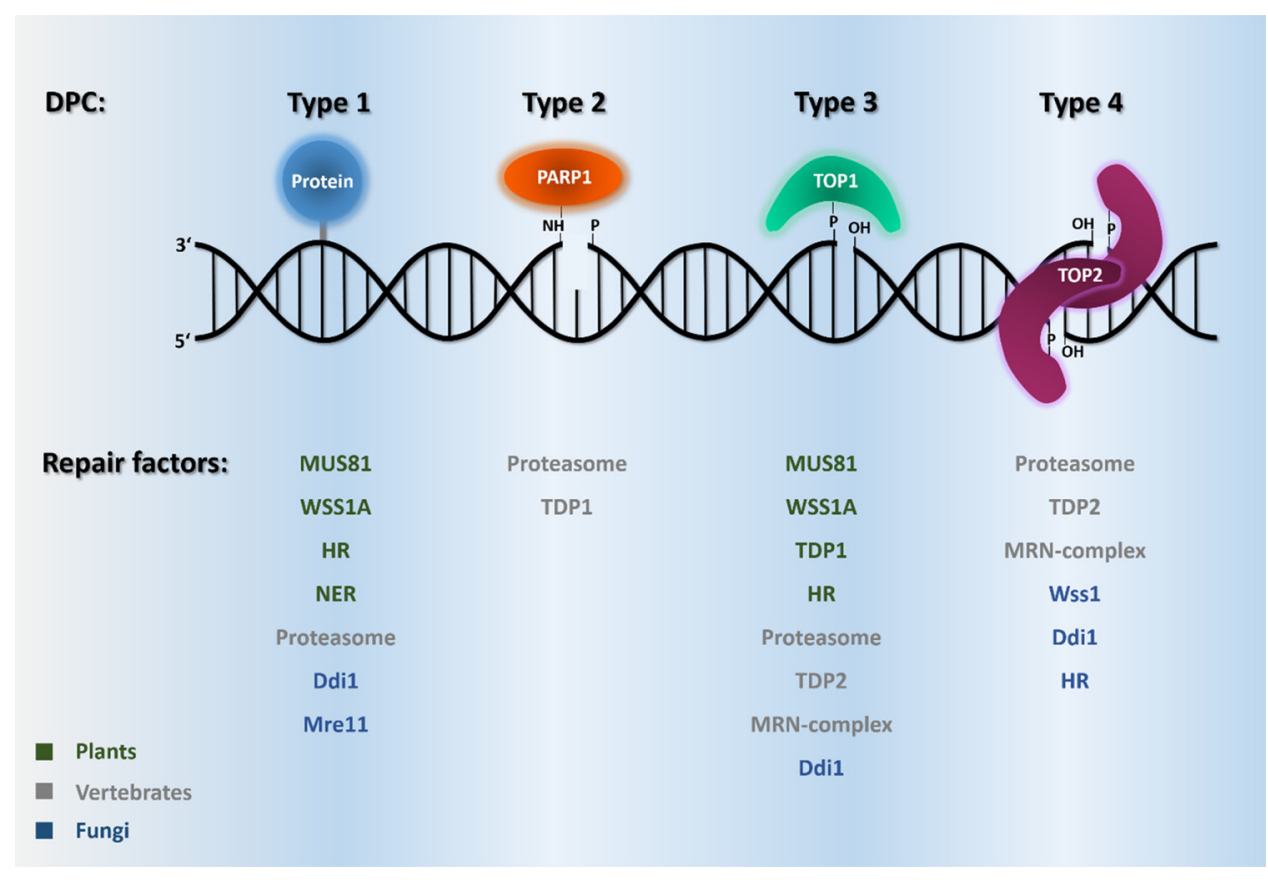

Fig. 2. Repair factors of different DPC types. In plants MUS81, WSS1A and HR contribute to the repair of Type 1 and 3 DPC. NER is an additional factor in the repair of Type 1 DPC, whereas TDP1 is acting in the repair of Type 3 DPC. In other eukaryotic organisms such as vertebrates or fungi, the involvement of further factors in DPC repair has been demonstrated. In vertebrates the proteasome is involved in the repair of Type 1-4 DPC. Additionally, TDP1 is an important factor in the repair of Type 2 DPC and TDP2 and the MRN-complex participate in the repair of Type 3 and 4 DPC. In fungi, Ddi1 contributes to repair of Type 1, 3 and 4 DPC and Mre11 was shown to be involved in the repair of Type 1 DPC. In fungi, it was also demonstrated that Wss1 and HR are contributing to the repair of Type 4 DPC.

$[81,82]$.

\subsection{Enzymatic hydrolysis of a DPC}

Besides the protein and the DNA part of a DPC, the crosslink bond itself can also be directly resolved. TDP1 (Tyrosyl DNA phosphodies terase 1), for example, is a specialized enzyme capable of hydrolyzing $3^{\prime}$ adducts of bulky lesions. It was postulated to be involved in the re pair of both Type 3 and Type 2 DPC $[79,83]$. Its function in the repair of Type 2 DPC, however, has only recently been discovered. In mouse fi broblasts, TDP1 is able to resolve the crosslink between the $3^{\prime}$ sugar phosphate of the DNA and a lysine primary amine of PARP1 after preceding proteolysis of PARP1 by the proteasome [79]. Its function in the repair of Type 3 DPC, on the other hand, has already been ex tensively examined. It was shown in yeast that the TDP1 homolog is able to hydrolyse the phosphodiester bond between the 3 ' phosphate of the DNA backbone and the active tyrosyl residue of Top1 [84]. Therefore, there are several underlying regulatory mechanisms. A di rect interaction of Parp1 and Tdp1 was demonstrated to result in the $\mathrm{N}$ terminal PARylation of Tdp1 thereby stabilizing and recruiting it to Type 3 DPC in proliferating cells [85]. Tdp1 can also become sumoy lated at lysine 111, which leads to the recruitment to Type 3 DPC in transcriptionally active areas $[86,87]$. If a Type 3 DPC is located on the leading strand during replication, this can lead to a replication fork run off or cleavage of the replication fork, thereby producing a DSB. In response to this, Tdp1 becomes phosphorylated and thus recruited to the Type 3 DPC induced DSB $[58,86,88]$. As the crosslink is inaccessible due to the size of Top1, a preceding partial degradation by the pro teasome is needed before Tdp1 can hydrolyse the phosphodiester bond $[75,89,90]$. Following crosslink hydrolysis, a $3^{\prime}$ phosphate remains at the DNA, which prevents simple re ligation, meaning further processing of the lesion is required. It was shown that PNKP (Polynucleotide kinase phosphatase) removes the $3^{\prime}$ phosphate from the DNA, and subsequent BER is responsible for sealing the nick [91].

Studies in yeast cells demonstrated that only mutants deficient in Tdp1 and at least one other repair enzyme exhibit hypersensitivity to CPT. Thus, Tdp1 in yeast serves as a backup pathway in the repair of Type 3 DPC [92,93]. In vertebrate cells, however, the knock out of the TDP1 gene alone was sufficient to mediate hypersensitivity to CPT [85,94]. This suggests a distinct relevance of Tdp1 in DPC repair for different eukaryotic organisms. Studies of the TDP1 enzyme in Arabi dopsis indicated a similar function in plants as in yeast. The phenotype and sensitivity to crosslinking agents of the Attdp1 single mutant did not differ from the wild type. In combination with mutations in WSS1A or MUS81, however, a synergistic effect could be observed. The double mutants exhibited an increased number of dead cells in the root mer istem as well as an enhanced sensitivity to CPT. This implies that TDP1 serves as a backup pathway for the repair of Type 3 DPC in plants [1].

TDP2 is another specialized enzyme in vertebrates whose function is associated with the hydrolysis of the two phosphotyrosyl bonds be tween Top2 and the DNA. TDP2 prefers to process the $5^{\prime}$ phosphotyr osyl termini of Type 4 DPC, but also has a weaker ability to dissolve $3^{\prime}$ phosphotyrosyl bonds from Type 3 DPC. Thus, vertebrate cells that are deficient in TDP2 depict hypersensitivity to etoposide and, in combi nation with a mutation in TDP1, an additive effect on susceptibility to CPT $[95,96]$. This signifies that apart from its function in the repair of Type 4 DPC, TDP2 is needed in a backup pathway to resolve Type 3 DPC in the absence of TDP1 in vertebrates. Regarding regulation, phosphorylation of the serine 60 residue of TDP2 is necessary to acti vate its phosphodiesterase activity [97]. In order to hydrolyse the crosslink, TDP2 first needs to gain access to it. This can occur via two different ways. The first is the preceding proteolytic degradation of the protein via the proteasome. In a second way, the SUMO E3 Ligase ZNT451/ZATT (Zinc finger protein Associated with TDP2 and TOP2) was demonstrated to sumoylate TOP2 thereby inducing a conforma tional change of the protein. In addition to this function, ZNT451/ZATT is able to recruit and activate TDP2. Due to the conformational change of TOP2, TDP2 is subsequently capable to gain access to the crosslink without preceding proteolysis [98,99]. After successful hydrolysis of the crosslink, the resulting DSB can be repaired directly by non homologous end joining [100].

In the search for a plant homolog, Confalonieri and his group were able to identify three homologous isoforms of human TDP2 in plants, which are distributed differently amongst the phylogenetic groups. Dicotyledonous plants such as Arabidopsis harbour only the first iso form TDP2 $\alpha$, whereas monocotyledonous plants such as maize and rice often possess two isoforms [101]. Initial analyses in Medicago truncatula suspension cultures have already shown that the overexpression of TDP2 $\alpha$ leads to a tolerance towards etoposide [102]. This indicates that the function of TDP2 in plants might be similar to the function in 


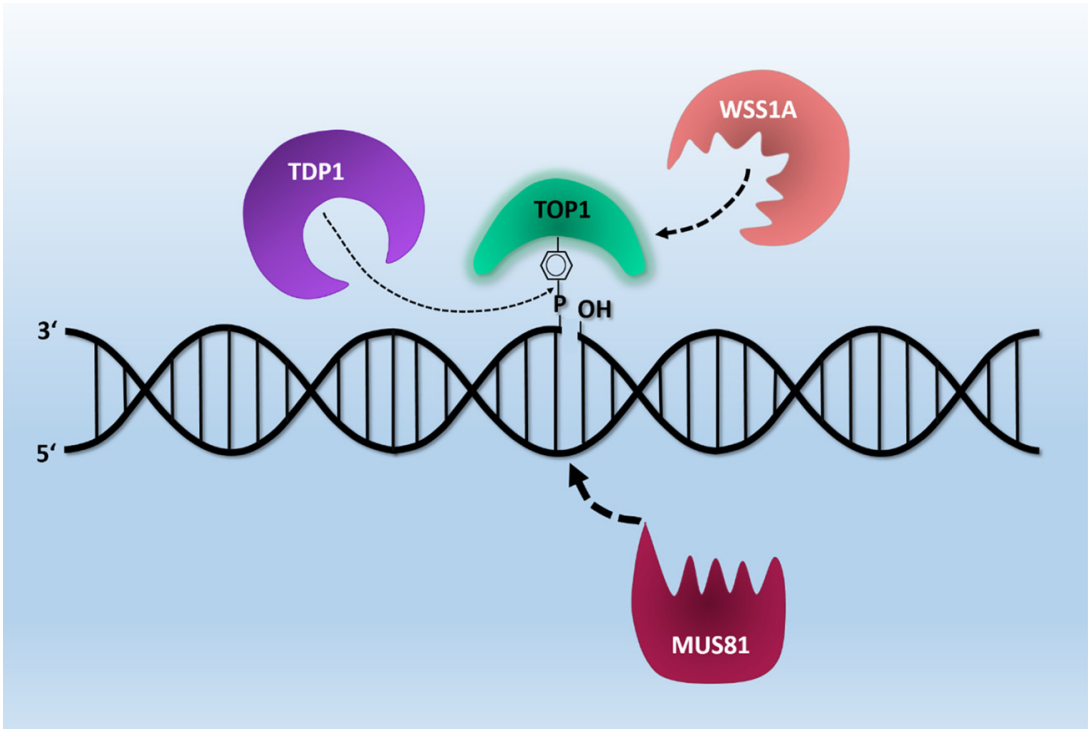

Fig. 3. Repair of Type 3 DPC in plants. Type 3 DPC can be resolved at least via three different pathways in plants. The most favoured way is the repair by endonucleolytic cleavage of the DNA by MUS81, whereas proteolytic degradation of TOP1 by WSS1A represents the second most preferred way. The phosphodiesterbond of Type 3 DPC can also be directly hydrolysed by TDP1. This, however, only occurs to a smaller extent and thus hydrolysis by TDP1 serves more as a backup pathway only when WSS1A or MUS81 are absent.

humans, but this issue remains to be analysed further (Fig. 2).

\section{Interplay of different DPC repair factors in plants}

Initial results revealed that at least three different independently working factors contribute to DPC repair in plants. The endonuclease MUS81 endonucleolytically cleaves the DNA part of a DPC, the protease WSS1A degrades the protein part and the phosphodiesterase TDP1 is able to hydrolyse the crosslink bond between TOP1 and the DNA. Various analyses of the respective mutant lines, such as the comparison of the root lengths and number of dead cells in the root meristem or exposure to the crosslinking agents cisplatin or CPT, revealed to what extent these factors contribute to DPC repair in plants. For the repair of Type 1 DPC, it was demonstrated that both the Atwss $1 A$ and the Atmus 81 mutant displayed enhanced sensitivity to cisplatin, indicating that both factors are involved in the repair of Type 1 DPC. As the Atwss1A mus81 double mutant exhibited an increased number of dead cells in the root meristem and an additive effect towards cisplatin, in comparison to the single mutant lines, it was postulated that WSS1A and MUS81 work in parallel pathways. However, since the Atwss1A mutant exhibited an even more enhanced sensitivity to cisplatin com pared to the Atmus 81 mutant, it can be concluded that proteolytic de gradation by WSS1A is the main pathway in the repair of Type 1 DPC, although MUS81 dependent repair also plays an important role. In the repair of Type 3 DPC, on the other hand, different sensitivities upon exposure to CPT revealed that endonucleolytic cleavage of the DNA by MUS81 is the favoured pathway, while proteolytic degradation by WSS1A is the second most preferred pathway. As Attdp1 mutant lines only displayed sensitivity to CPT when one of the two other factors was missing as well, it was concluded that TDP1 only serves as backup pathway in the repair of Type 3 DPC and thus plays only a minor role in plants [1] (Fig. 3). Information about the repair of Type 2 and 4 DPC in plants is still missing and will be an interesting topic for future research.

\section{Conclusion and perspectives}

DPC are highly toxic lesions and therefore pose a major threat to genome integrity in plants. In order to ensure the viability of cells, this damage must be detected and repaired in a timely manner. Research in DPC repair in plants has only just begun and therefore many details are still lacking. As most proteins identified so far are evolutionary con served, a wide variety of factors may be unveiled soon in plants. As so many factors from different repair networks seem to be involved in DPC repair, and proteins never before connected to DNA repair were recently uncovered in their function in DPC repair, this further high lights the importance of this research field. It will be an exciting task in the future to unravel further factors involved in plant DPC repair and to understand the complicated regulation network of the individual pro teins, as our current knowledge represents only the tip of the iceberg.

\section{Declaration of Competing Interest}

The authors declare no competing interests.

\section{Acknowledgments}

The authors want to thank Amy Whitbread for critically proof reading the manuscript and the Deutsche Forschungsgemeinschaft for funding (Grant Pu 137/22 1).

\section{References}

[1] J. Enderle, A. Dorn, N. Beying, O. Trapp, H. Puchta, The protease WSS1A, the endonuclease MUS81, and the phosphodiesterase TDP1 are involved in independent pathways of DNA-protein crosslink repair in plants, Plant Cell 31 (2019) 775-790, https://doi.org/10.1105/tpc.18.00824.

[2] H. Ide, M.I. Shoulkamy, T. Nakano, M. Miyamoto-Matsubara, A.M.H. Salem, Repair and biochemical effects of DNA-protein crosslinks, Mutat. Res. Mol. Mech. Mutagen. 711 (2011) 113-122, https://doi.org/10.1016/j.mrfmmm.2010.12.007.

[3] T. Nakano, X. Xu, A.M.H. Salem, M.I. Shoulkamy, H. Ide, Radiation-induced DNA-protein cross-links: mechanisms and biological significance, Free Radic. Biol. Med. 107 (2017) 136-145, https://doi.org/10.1016/j.freeradbiomed.2016.11. 041.

[4] J.A. Swenberg, K. Lu, B.C. Moeller, L. Gao, P.B. Upton, J. Nakamura, T.B. Starr, Endogenous versus exogenous DNA adducts: their role in carcinogenesis, epidemiology, and risk assessment, Toxicolog. Sci. Official J. Soc. Toxico. 120 (2011) 130-145, https://doi.org/10.1093/toxsci/kfq371.

[5] Y.-i. Tsukada, J. Fang, H. Erdjument-Bromage, M.E. Warren, C.H. Borchers, P. Tempst, Y. Zhang, Histone demethylation by a family of JmjC domain-containing proteins, Nature 439 (2006) 811-816, https://doi.org/10.1038/ nature 04433 .

[6] J.F. Turrens, Mitochondrial formation of reactive oxygen species, J. Physiol. 552 (2003) 335-344, https://doi.org/10.1113/jphysiol.2003.049478.

[7] T.F. Beckhauser, J. Francis-Oliveira, R. de Pasquale, Reactive oxygen species: physiological and physiopathological effects on synaptic plasticity, J. Exp. Neurosci. 10 (2016) 23-48, https://doi.org/10.4137/JEN.S39887.

[8] J. Enderle, A. Dorn, H. Puchta, DNA- and DNA-Protein-Crosslink repair in plants, Int. J. Mol. Sci. 20 (2019) 4340, https://doi.org/10.3390/ijms20174304.

[9] M.J. Solomon, A. Varshavsky, Formaldehyde-mediated DNA-protein crosslinking: a probe for in vivo chromatin structures, Proc. Natl. Acad. Sci. U.S.A. 82 (1985) 6470-6474, https://doi.org/10.1073/pnas.82.19.6470.

[10] S.M. Cohen, S.J. Lippard, Cisplatin: from DNA damage to cancer chemotherapy, Progress in Nucleic Acid Research and Molecular Biology 63, Academic Press, 2001, pp. 93-130.

[11] C.-H. Liu, A. Finke, M. Díaz, W. Rozhon, B. Poppenberger, T. Baubec, A. Pecinka, Repair of DNA damage induced by the cytidine analog zebularine requires ATR 
and ATM in Arabidopsis, Plant Cell 27 (2015) 1788-1800, https://doi.org/10. 1105/tpc.114.135467.

[12] D.V. Santi, A. Norment, C.E. Garrett, Covalent bond formation between a DNAcytosine methyltransferase and DNA containing 5-azacytosine, PNAS 81 (1984) 6993-6997, https://doi.org/10.1073/pnas.81.22.6993.

[13] S. Barker, M. Weinfeld, D. Murray, DNA-protein crosslinks: their induction, repair, and biological consequences, Mutat. Res. Mutat. Res. 589 (2005) 111-135, https://doi.org/10.1016/j.mrrev.2004.11.003.

[14] H. Ide, T. Nakano, A.M.H. Salem, M.I. Shoulkamy, DNA-protein cross-links: for midable challenges to maintaining genome integrity, DNA Repair 71 (2018) 190-197, https://doi.org/10.1016/j.dnarep.2018.08.024.

[15] R.P. Rastogi, Richa, A. Kumar, M.B. Tyagi, P.S. Rajeshwar, Molecular mechanisms of ultraviolet radiation-induced DNA damage and repair, J. Nucleic Acids 2010 (2010) 592980, https://doi.org/10.4061/2010/592980.

[16] M.S. DeMott, E. Beyret, D. Wong, B.C. Bales, J.-T. Hwang, M.M. Greenberg, B. Demple, Covalent trapping of human DNA polymerase beta by the oxidative DNA lesion 2-deoxyribonolactone, J. Biol. Chem. 277 (2002) 7637-7640, https:// doi.org/10.1074/jbc.C100577200.

[17] R. Prasad, J.K. Horton, P.D. Chastain II, N.R. Gassman, B.D. Freudenthal, E.W. Hou, S.H. Wilson, Suicidal cross-linking of PARP-1 to AP site intermediates in cells undergoing base excision repair, Nucleic Acids Res. 42 (2014) 6337-6351, https://doi.org/10.1093/nar/gku288.

[18] S.N. Khodyreva, R. Prasad, E.S. Ilina, M.V. Sukhanova, M.M. Kutuzov, Y. Liu, E.W. Hou, S.H. Wilson, O.I. Lavrik, Apurinic/apyrimidinic (AP) site recognition by the 5'-dRP/AP lyase in poly(ADP-ribose) polymerase-1 (PARP-1, Proc. Natl. Acad. Sci. U.S.A. 107 (2010) 22090-22095, https://doi.org/10.1073/pnas.1009182107.

[20] J. Murai, S. Huang, B.B. Das, A. Renaud, Y. Zhang, J.H. Doroshow, J. Ji, S. Takeda, Y. Pommier, Trapping of PARP1 and PARP2 by clinical PARP inhibitors, Cancer Res. 72 (2012) 5588-5599, https://doi.org/10.1158/0008-5472.CAN-12-2753.

[21] E. Babiychuk, P.B. Cottrill, S. Storozhenko, M. Fuangthong, Y. Chen, M.K. O’Farrell, M. van Montagu, D. Inzé, S. Kushnir, Higher plants possess two structurally different poly(ADP-ribose) polymerases, Plant J. 15 (1998) 635-645, https://doi.org/10.1046/j.1365-313x.1998.00240.x.

[22] T. Klemm, A. Mannuß, D. Kobbe, A. Knoll, O. Trapp, A. Dorn, H. Puchta, The DNA translocase RAD5A acts independently of the other main DNA repair pathways, and requires both its ATPase and RING domain for activity in Arabidopsis thaliana, Plant J. 91 (2017) 725-740, https://doi.org/10.1111/tpj.13602.

[23] D. Rissel, E. Peiter, Poly(ADP-Ribose) polymerases in plants and their human counterparts: parallels and peculiarities, Int. J. Mol. Sci. 20 (2019) 1638, https:// doi.org/10.3390/ijms20071638.

[24] J.L. Quiñones, U. Thapar, K. Yu, Q. Fang, R.W. Sobol, B. Demple, Enzyme mechanism-based, oxidative DNA-protein cross-links formed with DNA polymerase $\beta$ in vivo, Proc. Natl. Acad. Sci. U.S.A. 112 (2015) 8602-8607, https://doi.org/10. 1073/pnas.1501101112.

[25] T. Roldán-Arjona, R.R. Ariza, D. Córdoba-Cañero, DNA base excision repair in plants: an unfolding story with familiar and novel characters, Front. Plant Sci. 10 (2019) 1055, https://doi.org/10.3389/fpls.2019.01055.

[26] A. Amoroso, L. Concia, C. Maggio, C. Raynaud, C. Bergounioux, E. Crespan, R. Cella, G. Maga, Oxidative DNA damage bypass in Arabidopsis thaliana requires DNA polymerase $\lambda$ and proliferating cell nuclear antigen 2, Plant Cell 23 (2011) 806-822, https://doi.org/10.1105/tpc.110.081455.

[27] E. Mentegari, M. Kissova, L. Bavagnoli, G. Maga, E. Crespan, DNA polymerases $\lambda$ and $\beta$ : the double-edged swords of DNA repair, Genes (Basel) 7 (2016) 57, https:// doi.org/10.3390/genes7090057.

[28] J.C. Wang, DNA topoisomerases, Annu. Rev. Biochem. 65 (1996) 635-692, https://doi.org/10.1146/annurev.bi.65.070196.003223.

[29] J.C. Connelly, D.R.F. Leach, Repair of DNA covalently linked to protein, Mol. Cell 13 (2004) 307-316, https://doi.org/10.1016/S1097-2765(04)00056-5.

[30] Y.H. Hsiang, R. Hertzberg, S. Hecht, L.F. Liu, Camptothecin induces protein-linked DNA breaks via mammalian DNA topoisomerase I, J. Biol. Chem. 260 (1985) 14873-14878.

[31] D.A. Burden, P.S. Kingma, S.J. Froelich-Ammon, M.-A. Bjornsti, M.W. Patchan, R.B. Thompson, N. Osheroff, Topoisomerase II etoposide interactions direct the formation of drug-induced Enzyme-DNA cleavage complexes, J. Biol. Chem. 271 (1996) 29238-29244, https://doi.org/10.1074/jbc.271.46.29238.

[32] P. Pourquier, L.M. Ueng, G. Kohlhagen, A. Mazumder, M. Gupta, K.W. Kohn, Y. Pommier, Effects of uracil incorporation, DNA mismatches, and abasic sites on cleavage and religation activities of mammalian topoisomerase I, J. Biol. Chem. 272 (1997) 7792-7796, https://doi.org/10.1074/jbc.272.12.7792.

[33] B.N. Singh, S.K. Sopory, M.K. Reddy, Plant DNA topoisomerases: structure, function, and cellular roles in plant development, Crit. Rev. Plant Sci. 23 (2004) 251-269, https://doi.org/10.1080/07352680490452816.

[34] A. Dorn, H. Puchta, Analyzing somatic DNA repair in Arabidopsis meiotic mutants, in: M. Pradillo, S. Heckmann (Eds.), Plant Meiosis: Methods and Protocols, Springer, New York, New York, NY, 2020, pp. 359-366.

[35] B. Vaz, M. Popovic, K. Ramadan, DNA-Protein crosslink proteolysis repair, Trends Biochem. Sci. 42 (2017) 483-495, https://doi.org/10.1016/j.tibs.2017.03.005.

[36] T. Nakano, S. Morishita, A. Katafuchi, M. Matsubara, Y. Horikawa, H. Terato, A.M.H. Salem, S. Izumi, S.P. Pack, K. Makino, H. Ide, Nucleotide excision repair and homologous recombination systems commit differentially to the repair of DNA-Protein crosslinks, Mol. Cell 28 (2007) 147-158, https://doi.org/10.1016/j. molcel.2007.07.029.

[37] I.G. Minko, A.J. Kurtz, D.L. Croteau, B. van Houten, T.M. Harris, R.S. Lloyd, Initiation of repair of DNA Polypeptide cross-links by the UvrABC nuclease, Biochemistry 44 (2005) 3000-3009, https://doi.org/10.1021/bi0478805.

[38] B. de Graaf, A. Clore, A.K. McCullough, Cellular pathways for DNA repair and damage tolerance of formaldehyde-induced DNA-protein crosslinks, DNA Repair 8 (2009) 1207-1214, https://doi.org/10.1016/j.dnarep.2009.06.007.

[39] T. Nakano, A. Katafuchi, M. Matsubara, H. Terato, T. Tsuboi, T. Masuda, T. Tatsumoto, S.P. Pack, K. Makino, D.L. Croteau, B. van Houten, K. Iijima, H. Tauchi, H. Ide, Homologous recombination but not nucleotide excision repair plays a pivotal role in tolerance of DNA-protein cross-links in mammalian cells, J. Biol. Chem. 284 (2009) 27065-27076, https://doi.org/10.1074/jbc.M109. 019174.

[40] M. Sabourin, J.L. Nitiss, K.C. Nitiss, K. Tatebayashi, H. Ikeda, N. Osheroff, Yeas recombination pathways triggered by topoisomerase II-mediated DNA breaks, Nucleic Acids Res. 31 (2003) 4373-4384, https://doi.org/10.1093/nar/gkg497.

[41] M.L. Orta, J.M. Calderón-Montaño, I. Domínguez, N. Pastor, E. Burgos-Morón, M. López-Lázaro, F. Cortés, S. Mateos, T. Helleday, 5-Aza-2'-deoxycytidine cause replication lesions that require Fanconi anemia-dependent homologous recombination for repair, Nucleic Acids Res. 41 (2013) 5827-5836, https://doi.org/ 10.1093/nar/gkt270.

[42] L. Ferrara, E.B. Kmiec, Camptothecin enhances the frequency of oligonucleotidedirected gene repair in mammalian cells by inducing DNA damage and activating homologous recombination, Nucleic Acids Res. 32 (2004) 5239-5248, https://doi. org/10.1093/nar/gkh822.

[43] A. Pecinka, M. Rosa, A. Schikora, M. Berlinger, H. Hirt, C. Luschnig, O. Mittelsten Scheid, Transgenerational stress memory is not a general response in Arabidopsis, PLoS One 4 (2009) e5202, https://doi.org/10.1371/journal.pone.0005202.

[44] H. Interthal, W.-D. Heyer, MUS81 encodes a novel Helix-hairpin-Helix protein involved in the response to UV- and methylation-induced DNA damage in Saccharomyces cerevisiae, Mol. Gen. Genet. 263 (2000) 812-827, https://doi.org/ $10.1007 / \mathrm{s} 004380000241$.

[45] M.N. Boddy, P.-H.L. Gaillard, W.H. McDonald, P. Shanahan, J.R. Yates, P. Russell, Mus81-Eme1 are essential components of a holliday junction resolvase, Cell 107 (2001) 537-548, https://doi.org/10.1016/S0092-8674(01)00536-0.

[46] V. Geuting, D. Kobbe, F. Hartung, J. Dürr, M. Focke, H. Puchta, Two distinct MUS81-EME1 complexes from Arabidopsis Process holliday junctions, Plant Physiol. 150 (2009) 1062-1071, https://doi.org/10.1104/pp.109.136846.

[47] P.-H.L. Gaillard, E. Noguchi, P. Shanahan, P. Russell, The endogenous Mus81 Eme1 complex resolves holliday junctions by a Nick and counternick mechanism, Mol. Cell 12 (2003) 747-759, https://doi.org/10.1016/S1097-2765(03)00342-3.

[48] L.J. Gaskell, F. Osman, R.J.C. Gilbert, M.C. Whitby, Mus81 cleavage of Holliday junctions: A failsafe for processing meiotic recombination intermediates? EMBO 26 (2007) 1891-1901, https://doi.org/10.1038/sj.emboj.7601645.

[49] X.-B. Chen, R. Melchionna, C.-M. Denis, P.-H.L. Gaillard, A. Blasina, I. van de Weyer, M.N. Boddy, P. Russell, J. Vialard, C.H. McGowan, Human Mus81Associated endonuclease cleaves holliday junctions in vitro, Mol. Cell 8 (2001) 1117-1127, https://doi.org/10.1016/S1097-2765(01)00375-6.

[50] C.L. Doe, J.S. Ahn, J. Dixon, M.C. Whitby, Mus81-Eme1 and Rqh1 involvement in processing stalled and collapsed replication forks, J. Biol. Chem. 277 (2002) 32753-32759, https://doi.org/10.1074/jbc.M202120200.

[51] A. Mannuss, S. Dukowic-Schulze, S. Suer, F. Hartung, M. Pacher, H. Puchta, RAD5A, RECQ4A, and MUS81 have specific functions in homologous recombination and define different pathways of DNA repair in Arabidopsis thaliana, Plant Cell 22 (2010) 3318-3330, https://doi.org/10.1105/tpc.110.078568.

[52] C. Liu, J.J. Pouliot, H.A. Nash, Repair of topoisomerase I covalent complexes in the absence of the tyrosyl-DNA phosphodiesterase Tdp1, PNAS 99 (2002) 14970-14975, https://doi.org/10.1073/pnas.182557199.

[53] M. Regairaz, Y.-W. Zhang, H. Fu, K.K. Agama, N. Tata, S. Agrawal, M.I. Aladjem, Y. Pommier, Mus81-mediated DNA cleavage resolves replication forks stalled by topoisomerase I-DNA complexes, J. Cell Biol. 195 (2011) 739-749, https://doi. org/10.1083/jcb.201104003.

[54] R.S. Williams, J.S. Williams, J.A. Tainer, Mre11-Rad50-Nbs1 is a keystone complex connecting DNA repair machinery, double-strand break signaling, and the chromatin template, Biochem. Cell Biol. 85 (2007) 509-520, https://doi.org/10. 1139/007-069.

[55] M.E. Gallego, M. Jeanneau, F. Granier, D. Bouchez, N. Bechtold, [Nachname nicht vorhanden], I. White, Disruption of the Arabidopsis RAD50 gene leads to plant sterility and MMS sensitivity, Plant J. 25 (2001) 31-41, https://doi.org/10.1111/ j.1365-313X.2001.00928.x.

[56] B.J. Lamarche, N.I. Orazio, M.D. Weitzman, The MRN complex in double-strand break repair and telomere maintenance, FEBS Lett. 584 (2010) 3682-3695, https://doi.org/10.1016/j.febslet.2010.07.029.

[57] J. Puizina, J. Siroky, P. Mokros, D. Schweizer, K. Riha, Mre11 deficiency in Arabidopsis is associated with chromosomal instability in somatic cells and Spo11dependent genome fragmentation during meiosis, Plant Cell 16 (2004) 1968-1978, https://doi.org/10.1105/tpc.104.022749.

[58] J. Stingele, R. Bellelli, S.J. Boulton, Mechanisms of DNA-protein crosslink repair, Nat. Rev. Mol. Cell Biol. 18 (2017) 563-573, https://doi.org/10.1038/nrm. 2017.56 .

[59] E. Hartsuiker, K. Mizuno, M. Molnar, J. Kohli, K. Ohta, A.M. Carr, Ctp1CtIP and Rad32Mre11 nuclease activity are required for Rec12Spo11 removal, but Rec12Spo11 removal is dispensable for other MRN-dependent meiotic functions, Mol. Cell. Biol. 29 (2009) 1671-1681, https://doi.org/10.1128/MCB.01182-08.

[60] T. Aparicio, R. Baer, M. Gottesman, J. Gautier, MRN, CtIP, and BRCA1 mediate repair of topoisomerase II-DNA adducts, J. Cell Biol. 212 (2016) 399-408, https:// doi.org/10.1083/jcb.201504005.

[61] J. Stingele, M.S. Schwarz, N. Bloemeke, P.G. Wolf, S. Jentsch, A DNA-Dependent Protease Involved in DNA-Protein Crosslink Repair, Cell 158 (2014) 327-338, https://doi.org/10.1016/j.cell.2014.04.053.

[62] N. Serbyn, A. Noireterre, I. Bagdiul, M. Plank, A.H. Michel, R. Loewith, 
B. Kornmann, F. Stutz, The aspartic protease Ddi1 contributes to DNA-Protein crosslink repair in yeast, bioRxiv (2019) 575860, https://doi.org/10.1101/ 575860 .

[63] J. Stingele, B. Habermann, S. Jentsch, DNA-protein crosslink repair: proteases as DNA repair enzymes, Trends Biochem. Sci. 40 (2015) 67-71, https://doi.org/10. 1016/j.tibs.2014.10.012.

[64] A. Mosbech, I. Gibbs-Seymour, K. Kagias, T. Thorslund, P. Beli, L. Povlsen, S.V. Nielsen, S. Smedegaard, G. Sedgwick, C. Lukas, R. Hartmann-Petersen, J. Lukas, C. Choudhary, R. Pocock, S. Bekker-Jensen, N. Mailand, DVC1 (C1orf124) is a DNA damage-targeting p97 adaptor that promotes ubiquitin-dependent responses to replication blocks, Nat. Struc. Amp; Mol. Bio. 19 (2012) 1084-1092, https://doi.org/10.1038/nsmb.2395.

[65] J. Stingele, R. Bellelli, F. Alte, G. Hewitt, G. Sarek, S.L. Maslen, S.E. Tsutakawa, A. Borg, S. Kjær, J.A. Tainer, J.M. Skehel, M. Groll, S.J. Boulton, Mechanism and Regulation of DNA- Protein Crosslink Repair by the DNA-Dependent Metalloprotease SPRTN, Mol. Cell 64 (2016) 688-703, https://doi.org/10.1016/j. molcel.2016.09.031

[66] J.P. Duxin, J.M. Dewar, H. Yardimci, J.C. Walter, Repair of a DNA-Protein crosslink by replication-coupled proteolysis, Cell 159 (2014) 346-357, https:// doi.org/10.1016/j.cell.2014.09.024.

[67] D.J. Clarke, G. Mondesert, M. Segal, B.L. Bertolaet, S. Jensen, M. Wolff, M. Henze, S.I. Reed, Dosage suppressors of pds1 implicate ubiquitin-associated domains in checkpoint control, Mol. Cell. Biol. 21 (2001) 1997-2007, https://doi.org/10. 1128/MCB.21.6.1997-2007.2001

[68] L. Kaplun, R. Tzirkin, A. Bakhrat, N. Shabek, Y. Ivantsiv, D. Raveh, The DNA damage-inducible UbL-UbA protein Ddi1 participates in Mec1-mediated degradation of Ho endonuclease, Mol. Cell. Biol. 25 (2005) 5355-5362, https://doi. org/10.1128/MCB.25.13.5355-5362.2005.

[69] S. Koizumi, T. Irie, S. Hirayama, Y. Sakurai, H. Yashiroda, I. Naguro, H. Ichijo, J. Hamazaki, S. Murata, I. Dikic, The aspartyl protease DDI2 activates Nrf1 to compensate for proteasome dysfunction, eLife 5 (2016) e18357, , https://doi.org/ 10.7554/eLife.18357.

[70] L.M. Farmer, A.J. Book, K.-H. Lee, Y.-L. Lin, H. Fu, R.D. Vierstra, The RAD23 family provides an essential connection between the $26 \mathrm{~S}$ proteasome and ubiquitylated proteins in Arabidopsis, Plant Cell 22 (2010) 124-142, https://doi.org/ 10.1105/tpc.109.072660.

[71] I.-C. Jang, Q.-W. Niu, S. Deng, P. Zhao, N.-H. Chua, Enhancing protein stability with retained biological function in transgenic plants, Plant J. 72 (2012) 345-354, https://doi.org/10.1111/j.1365-313X.2012.05060.x.

[72] J.-F. Trempe, K.G. Šašková, M. Sivá, C.D.H. Ratcliffe, V. Veverka, A. Hoegl, M. Ménade, X. Feng, S. Shenker, M. Svoboda, M. Kožíšek, J. Konvalinka, K. Gehring, Structural studies of the yeast DNA damage-inducible protein Ddi1 reveal domain architecture of this eukaryotic protein family, Sci. Rep. 6 (2016) 33671, https://doi.org/10.1038/srep33671.

[73] M. Svoboda, J. Konvalinka, J.-F. Trempe, K. Grantz Saskova, The yeast proteases Ddi1 and Wss1 are both involved in the DNA replication stress response, DNA Repair 80 (2019) 45-51, https://doi.org/10.1016/j.dnarep.2019.06.008.

[74] D.M. Krylov, E.V. Koonin, Correspondence: A novel family of predicted retrovirallike aspartyl proteases with a A novel family of predicted retroviral-like aspartyl proteases with a possible key role in eukaryotic cell cycle control, Curr. Biol. 11 (2001) 584-587, https://doi.org/10.1016/S0960-9822(01)00357-8.

[75] S.D. Desai, T.K. Li, A. Rodriguez-Bauman, E.H. Rubin, L.F. Liu, Ubiquitin/26S proteasome-mediated degradation of topoisomerase I as a resistance mechanism to camptothecin in tumor cells, Cancer Res. 61 (2001) 5926-5932.

[76] S.D. Desai, L.F. Liu, D. Vazquez-Abad, P. D’Arpa, Ubiquitin-dependent destruction of topoisomerase I is stimulated by the antitumor drug camptothecin, J. Biol. Chem. 272 (1997) 24159-24164, https://doi.org/10.1074/jbc.272.39.24159.

[77] C.-P. Lin, Y. Ban, Y.L. Lyu, S.D. Desai, L.F. Liu, A ubiquitin-proteasome pathway for the repair of topoisomerase I-DNA covalent complexes, J. Biol. Chem. 283 (2008) 21074-21083, https://doi.org/10.1074/jbc.M803493200.

[78] Y. Mao, S.D. Desai, C.Y. Ting, J. Hwang, L.F. Liu, $26 \mathrm{~S}$ proteasome-mediated degradation of topoisomerase II cleavable complexes, J. Biol. Chem. 276 (2001) 40652-40658, https://doi.org/10.1074/jbc.M104009200.

[79] R. Prasad, J.K. Horton, D.-P. Dai, S.H. Wilson, Repair pathway for PARP-1 DNAprotein crosslinks, DNA Repair 73 (2019) 71-77, https://doi.org/10.1016/j. dnarep.2018.11.004.

[80] N.B. Larsen, A.O. Gao, J.L. Sparks, I. Gallina, R.A. Wu, M. Mann, M. Räschle, J.C. Walter, J.P. Duxin, Replication-Coupled DNA-Protein Crosslink Repair by SPRTN and the Proteasome in Xenopus Egg Extracts, Mol. Cell 73 (2019) 574-588, https://doi.org/10.1016/j.molcel.2018.11.024.

[81] K. Dreher, J. Callis, Ubiquitin, hormones and biotic stress in plants, Ann. Bot. 99 (2007) 787-822, https://doi.org/10.1093/aob/mcl255.

[82] J. Kurepa, J.A. Smalle, Structure, function and regulation of plant proteasomes, Biochimie 90 (2008) 324-335, https://doi.org/10.1016/j.biochi.2007.07.019.

[83] Y. Pommier, J.M. Barcelo, V.A. Rao, O. Sordet, A.G. Jobson, L. Thibaut, Z.H. Miao, J.A. Seiler, H. Zhang, C. Marchand, K. Agama, J.L. Nitiss, C. Redon,
Repair of topoisomerase i-mediated DNA damage, in: K. Moldave (Ed.), Progress in Nucleic Acid Research and Molecular Biology, Academic Press, New York, 2006, pp. 179-229.

[84] J.J. Pouliot, K.C. Yao, C.A. Robertson, H.A. Nash, Yeast gene for a Tyr-DNA phosphodiesterase that repairs topoisomerase I complexes, Science 286 (1999) 552-555, https://doi.org/10.1126/science.286.5439.552.

[85] B.B. Das, S. Antony, S. Gupta, T.S. Dexheimer, C.E. Redon, S. Garfield, Y. Shiloh, Y. Pommier, Optimal function of the DNA repair enzyme TDP1 requires its phosphorylation by ATM and/or DNA-PK, EMBO J. 28 (2009) 3667-3680, https:// doi.org/10.1038/emboj.2009.302.

[86] Y. Pommier, S.-y.N. Huang, R. Gao, B.B. Das, J. Murai, C. Marchand, Tyrosyl-DNA phosphodiesterases (TDP1 and TDP2), DNA Repair 19 (2014) 114-129, https:// doi.org/10.1016/j.dnarep.2014.03.020

[87] J.J.R. Hudson, S.-C. Chiang, O.S. Wells, C. Rookyard, S.F. El-Khamisy, SUMO modification of the neuroprotective protein TDP1 facilitates chromosomal singlestrand break repair, Nat. Commun. 3 (2012), https://doi.org/10.1038/ ncomms1739.

[88] D. Strumberg, A.A. Pilon, M. Smith, R. Hickey, L. Malkas, Y. Pommier, Conversion of topoisomerase I cleavage complexes on the leading strand of ribosomal DNA into 5'-phosphorylated DNA double-strand breaks by replication runoff, Mol. Cell. Biol. 20 (2000) 3977-3987, https://doi.org/10.1128/mcb.20.11.3977-3987. 2000.

[89] L. Debéthune, G. Kohlhagen, A. Grandas, Y. Pommier, Processing of nucleopeptides mimicking the topoisomerase I-DNA covalent complex by tyrosyl-DNA phosphodiesterase, Nucleic Acids Res. 30 (2002) 1198-1204, https://doi.org/10. 1093/nar/30.5.1198.

[90] H. Interthal, J.J. Champoux, Effects of DNA and protein size on substrate cleavage by human tyrosyl-DNA phosphodiesterase 1, Biochem. J. 436 (2011) 559-566, https://doi.org/10.1042/BJ20101841.

[91] I. Plo, Z.-Y. Liao, J.M. Barceló, G. Kohlhagen, K.W. Caldecott, M. Weinfeld, Y. Pommier, Association of XRCC1 and tyrosyl DNA phosphodiesterase (Tdp1) for the repair of topoisomerase I-mediated DNA lesions, DNA Repair 2 (2003) 1087-1100, https://doi.org/10.1016/S1568-7864(03)00116-2.

[92] J.R. Vance, T.E. Wilson, Yeast Tdp1 and Rad1-Rad10 function as redundant pathways for repairing Top1 replicative damage, PNAS 99 (2002) 13669-13674, https://doi.org/10.1073/pnas.202242599.

[93] A.S. Kawale, L.F. Povirk, Tyrosyl-DNA phosphodiesterases: rescuing the genome from the risks of relaxation, Nucleic Acids Res. 46 (2018) 520-537, https://doi. org/10.1093/nar/gkx1219.

[94] J. Murai, S. Huang, B.B. Das, T.S. Dexheimer, S. Takeda, Y. Pommier, Tyrosyl-DNA phosphodiesterase 1 (TDP1) repairs DNA damage induced by topoisomerases I and II and base alkylation in vertebrate cells, J. Biol. Chem. 287 (2012) 12848-12857, https://doi.org/10.1074/jbc.M111.333963.

[95] Z. Zeng, F. Cortés-Ledesma, S.F. El Khamisy, K.W. Caldecott, TDP2/TTRAP is the major 5'-Tyrosyl DNA phosphodiesterase activity in vertebrate cells and is critical for cellular resistance to topoisomerase II-induced DNA damage*, J. Biol. Chem. 286 (2011) 403-409, https://doi.org/10.1074/jbc.M110.181016.

[96] Z. Zeng, A. Sharma, L. Ju, J. Murai, L. Umans, L. Vermeire, Y. Pommier, S. Takeda, D. Huylebroeck, K.W. Caldecott, S.F. El-Khamisy, TDP2 promotes repair of topoisomerase I-mediated DNA damage in the absence of TDP1, Nucleic Acids Res. 40 (2012) 8371-8380, https://doi.org/10.1093/nar/gks622.

[97] K. Bian, N.R. Muppani, L. Elkhadragy, W. Wang, C. Zhang, T. Chen, S. Jung, O.M. Seternes, W. Long, ERK3 regulates TDP2-mediated DNA damage response and chemoresistance in lung cancer cells, Oncotarget 7 (2016) 6665-6675, https://doi.org/10.18632/oncotarget.6682.

[98] G. Zagnoli-Vieira, K.W. Caldecott, TDP2, TOP2, and SUMO: what is ZATT about? Cell Res. 27 (2017) 1405-1406, https://doi.org/10.1038/cr.2017.147.

[99] M.J. Schellenberg, J.A. Lieberman, A. Herrero-Ruiz, L.R. Butler, J.G. Williams, A.M. Muñoz-Cabello, G.A. Mueller, R.E. London, F. Cortés-Ledesma, R.S. Williams, ZATT (ZNF451)-mediated resolution of topoisomerase 2 DNA-protein cross-links, Science 357 (2017) 1412-1416, https://doi.org/10.1126/science.aam6468.

[100] F. Gómez-Herreros, R. Romero-Granados, Z. Zeng, A. Alvarez-Quilón, C. Quintero, L. Ju, L. Umans, L. Vermeire, D. Huylebroeck, K.W. Caldecott, F. Cortés-Ledesma, TDP2-dependent non-homologous end-joining protects against topoisomerase II-induced DNA breaks and genome instability in cells and in vivo, PLoS Genet. 9 (2013) e1003226, , https://doi.org/10.1371/journal.pgen. 1003226.

[101] M. Confalonieri, M. Faè, A. Balestrazzi, M. Donà, A. Macovei, A. Valassi, G. Giraffa, D. Carbonera, Enhanced osmotic stress tolerance in Medicago truncatula plants overexpressing the DNA repair gene MtTdp2 $\alpha$ (tyrosyl-DNA phosphodiesterase 2), Plant Cell, J. Tissue Cult. Methods 116 (2014) 187-203, https:// doi.org/10.1007/s11240-013-0395-y.

[102] A. Macovei, M. Faè, M. Biggiogera, S. de Sousa Araújo, D. Carbonera, A. Balestrazzi, Ultrastructural and molecular analyses reveal enhanced nucleolar activity in Medicago truncatula cells overexpressing the MtTdp $2 \alpha$ gene, Front. Plant Sci. 9 (2018) 596, https://doi.org/10.3389/fpls.2018.00596. 
Karlsruher Institut für Technologie

\section{Repository KITopen}

Dies ist ein Postprint/begutachtetes Manuskript.

Empfohlene Zitierung:

Hacker, L.; Dorn, A.; Puchta, H.

Repair of DNA-protein crosslinks in plants.

2020. DNA repair, 87

doi:10.5445/IR/1000105337

Zitierung der Originalveröffentlichung:

Hacker, L.; Dorn, A.; Puchta, H.

Repair of DNA-protein crosslinks in plants.

2020. DNA repair, 87, Article No.102787.

doi:10.1016/j.dnarep.2020.102787 